Derecho del consumidor 


\section{El derecho del consumidor a la seguridad}

\section{Daniel Echaiz Moreno}

\section{La norma específica como punto de partida}

El Código de Protección y Defensa del Consumidor (Ley 29571) establece en el acápite a) del inciso 1.1 del artículo 1:

Artículo 1. Derechos de los consumidores

1.1 En los términos establecidos por el presente Código, los consumidores tienen los siguientes derechos:

a. Derecho a una protección eficaz respecto de los productos y servicios que, en condiciones normales o previsibles, representen riesgo o peligro para la vida, salud e integridad física.

\section{El consumidor y la importancia de su protección}

El 15 de marzo de 1962, el entonces presidente de Estados Unidos, John Fitzgerald Kennedy, en un célebre discurso ante el Congreso de su país, dijo: "Ser consumidor, por definición, nos incluye a todos [...]. Somos el grupo económico más grande en el mercado, que afecta y es afectado por casi todas las decisiones económicas públicas y privadas [...] pero es el único grupo importante cuyos puntos de vista a menudo no son escuchados". Allí nació la protección del consumidor, que luego se legisló e institucionalizó, primero en Estados Unidos, luego en Europa 
y por último en América Latina, y que llegó al Perú en 1991, con la dación de la primera Ley de Protección al Consumidor (Decreto Legislativo 716), a la cual siguió, en 1992, la creación de la Comisión de Protección al Consumidor, dentro de la estructura orgánica del Instituto Nacional de Defensa de la Competencia y de la Protección de la Propiedad Intelectual (Indecopi).

Se trataba de reconocer que en la relación de consumo (plasmada a través de la contratación) las partes intervinientes difieren una de la otra, mas no porque una sea "la parte fuerte" y la otra "la parte débil" - como antaño se sostenía -, sino porque una cuenta con más y/o mejor información que la otra, lo que implica el principio de asimetría informativa. Entonces, el Estado debe asumir un rol tuitivo y para ello establece el sistema de protección al consumidor, que, por cierto, no protege al consumidor per se, sino, stricto sensu, al consumidor final (precedente de observancia obligatoria contenido en la Resolución 101-96-TDC, caso Cheenyi vs. Konica), el cual podría ser incluso una persona jurídica (precedente de observancia obligatoria contenido en la Resolución 4222003-TDC, caso Moquillaza vs. Milne).

Antes de la corriente proconsumidor (que empezó, notoriamente, en 1962), el mercado era distinto, pues la empresa se mostraba como una insaciable máquina lucrativa, el empresario era el único a quien podía importarle el destino de la empresa, la información era un privilegio de los socios mayoritarios, existían solo las grandes empresas, y los monopolios se adueñaban íntegramente de los sectores económicos más rentables. Todo ello se traducía en el mundo del derecho, donde las relaciones económicas se plasmaban en un vetusto derecho comercial que sólo miraba a los comerciantes o a los actos de comercio. Pero eso fue hace más de cincuenta años, y desde entonces todo cambió. Hoy en día la empresa es el motor de la sociedad contemporánea, actúa con responsabilidad social corporativa, atiende a sus diversos grupos de interés, incorpora política de gobierno corporativo, convive con pequeñas y medianas empresas y se somete al marco regulatorio de la libre competencia.

El derecho, entonces, también cambió. Ya no es el otrora derecho comercial; hoy estamos ante el derecho empresarial que reconoce a la empresa como un fenómeno socioeconómico complejo (no inventado por abogados) en cuyo alrededor encontramos diversos grupos de interés: el inversionista mayoritario, el inversionista minoritario, el trabaja- 
dor, el acreedor, el consumidor, el Estado y la comunidad, entre otros. A todos les conviene el éxito de la empresa, aunque por diversas razones; así por ejemplo: al inversionista minoritario, para maximizar la rentabilidad de su inversión; al consumidor, para gozar de productos de calidad; y al Estado, para recaudar mayores ingresos por impuesto a la renta. Por consiguiente, la tarea actual del derecho empresarial es lograr una regulación jurídica integral, no una simple regulación jurídica, porque eso ya se consiguió: si enfocamos la relación empresa-trabajador, tenemos el derecho laboral, y si hacemos lo propio con la relación empresa-acreedor, tenemos el derecho concursal. Eso ya existe.

El reto hoy en día es conseguir una regulación jurídica integral, es decir, enfocar con realismo a la empresa y atender, a la vez, a todos los grupos de interés: ninguno es más importante que otro, pues todos son necesarios. ¿Qué hace una empresa sin inversionistas que se arriesguen por ella?, ¿o con trabajadores insatisfechos que van a la huelga?, ¿o con consumidores que organizan un boicot en el mercado? La tarea es ardua, pero es lo que corresponde en la actualidad. En esa dirección tiene que alinearse el Código de Protección y Defensa del Consumidor (Ley 29571), sin pretender una protección única, exclusiva, excluyente e irracional del consumidor, como si fuese el único grupo de interés y creyendo que la empresa es un ogro malvado, abusivo y despiadado. No se trata, pues, de ser exagerados: ni un mercado sin regulaciones (que devenga en anarquía), ni un mercado con regulaciones excesivas (que asfixie a todos). Se requiere un mercado con regulaciones adecuadas y razonables; por lo demás, este es el sustento de una economía social de mercado, siendo éste el régimen económico consagrado en nuestra Constitución Política.

En suma, la importancia de la protección del consumidor reposa en dos claras razones: por un lado, la superación de la antigua dicotomía "parte fuerte / parte débil" en la contratación; por otro, el reconocimiento de la asimetría informativa en la relación de consumo.

\section{El régimen constitucional económico y la protección al consumidor sin paternalismo}

La Constitución Política del Perú dedica el título III al régimen económico, título que empieza con el capítulo I, relativo a los principios generales, dentro de los cuales se ubica el siguiente artículo: 
Artículo 65.- El Estado defiende el interés de los consumidores y usuarios. Para tal efecto garantiza el derecho a la información sobre los bienes y servicios que se encuentran a su disposición en el mercado. Asimismo vela, en particular, por la salud y la seguridad de la población.

Atendiendo a su carácter constitucional, esta es la norma matriz de la regulación normativa de la protección al consumidor en el Perú. De ella se derivan tres funciones básicas del Estado:

a) El Estado asume un rol defensor del interés de los consumidores y los usuarios, aunque en realidad debería ser un rol tuitivo, es decir protector, en virtud del actual modelo económico (la economía social de mercado) que otorga al Estado la tarea regulatoria, mas no intervencionista, en la economía.

b) El Estado garantiza el derecho a la información que deberán ofrecer los proveedores sobre los bienes y los servicios que se encuentran en el mercado a disposición de los consumidores y los usuarios, precisamente para contrarrestar (en parte) la natural asimetría informativa.

c) El Estado vela en particular por la salud y la seguridad de la población, al estimar que se trata de dos bienes jurídicos de especial relevancia, por lo que merecen una mayor tutela estatal.

Todo lo anterior podríamos vincularlo sosteniendo que el Estado procura la protección del consumidor y, para ese cometido, garantiza que el proveedor le dará información al consumidor, lo que es especialmente trascendente cuando la relación de consumo involucra la salud o la seguridad del consumidor o usuario. En palabras de Alfredo Quispe Correa:

La empresa, como se sabe, busca utilidad. El consumidor, se supone, busca calidad y precio. De esa relación asimétrica entre la empresa y el consumidor, la ventaja marcha al lado de la empresa: tiene mayor capacidad económica para influir en la decisión del usuario y/o consumidor, lo que realiza a través de la publicidad y la propaganda, estudio de mercado, experiencias de laboratorio, etc. El usuario o consumidor se encuentra indefenso ante una campaña agresiva a favor de un producto, por lo que el Estado, o la asociación de consumidores, o quienes están encargados de proteger los llamados intereses difusos, deben intervenir para equilibrar la presión que se ejerce (2007: 111-112). 
Sin embargo, no confundamos lo antes expuesto con el paternalismo, que "es la tendencia a aplicar las formas de autoridad y protección propias del padre en la familia tradicional a relaciones sociales de otro tipo, como políticas" (Vega Castro-Sayán 2010: 180-181). Como bien explica Victorhugo Montoya Chávez (2009: 164): “[...] no solamente se requiere una orientación de las actividades económicas necesarias para el desarrollo real del país, sino también, en algunos casos, es imprescindible una intervención vigilante y controladora por parte del Estado". En ese sentido se pronuncia la sentencia del Tribunal Constitucional recaída en el expediente 2016-2004-AA/TC, cuando refiere que las políticas públicas que se realicen como expresión de obligaciones concretas para garantizar los derechos de las personas importa que tanto el Estado como la comunidad, a través de un deber de solidaridad, deban intentar conseguir aquellos bienes que les permitan el goce efectivo de sus derechos económicos. Esta regulación legal no tiene que ser paternalista, sino promotora de la actuación del consumidor diligente, informado y razonable.

Así, para Victorhugo Montoya Chávez (2009: 165),

[...] es menester enfatizar que la satisfacción de las necesidades del consumidor y del usuario (artículo 65 de la Constitución) es el punto de referencia que debe tenerse en cuenta al momento de determinar el desenvolvimiento eficiente del mercado, y es así como surge la función reguladora que debe cumplir. El control de los estándares de calidad del servicio, la razonabilidad del precio que se le asigne, el desarrollo sostenido del sector, la acción proactiva y efectiva en el cuidado del medio ambiente y la competencia técnica son consideradas como conductas a ser asumidas por los organismos reguladores, ya sea mediante acciones ex ante (regulaciones previas) como ex post (sanciones disuasivas para el infractor como para los distintos competidores de atentar contra los valores de un mercado eficiente y humano).

Véase, entonces, que el actual régimen constitucional económico tiende a la protección del consumidor, sin que ello suponga una actuación paternalista que, lejos de ser beneficiosa, termina siendo contraproducente para todos los que de una u otra manera están involucrados en el mercado. 


\section{El gobierno corporativo y la responsabilidad social corporativa como nuevos referentes para la actuación de las empresas}

La doctrina anglosajona desarrolló, en época reciente, una nueva institución jurídica, denominada corporate governance, que ha arribado al mundo romanogermánico con el nombre de gobierno corporativo, también conocido como gobernanza empresarial, buen gobierno corporativo, gobierno de las sociedades, etc. Se trata de un sistema dentro de la sociedad empresarial que incluye procedimientos, actividades (prácticas) e instituciones (normas) en cuanto a la relación entre los accionistas de la sociedad (titulares) y su administración (directorio y gerencia) (Martínez-Ortiz 2007: 42). En la medida de lo posible, se procura evitar la concentración de la propiedad y la administración de la empresa en las mismas manos, en aras de la transparencia de la marcha empresarial en el mercado. Especial atención merece la vinculación del gobierno corporativo con las relaciones de agencia, porque aquel pretende superar los costos asociados a la agencia (costo directo, costo de supervisión y monitoreo, costo de información y costo de garantía) que van más allá de la sola reducción de los costos de transacción (ocasionados por la agencia).

La teoría del gobierno corporativo también vincula a las empresas con la ética, lo que acaso se creía incongruente hace algunos años. Ante la pregunta: ¿existe alguna relación entre el buen gobierno corporativo y la ética empresarial?, Julio Salas Sánchez (2008: 348) responde:

Sí, la decisión de aplicar los principios de gobierno corporativo tiene que significar que la empresa está dispuesta a crear en ella una cultura de buen gobierno corporativo, decisión que, por esencia, conlleva una actuación ética, responsable, transparente, con todo lo que esas experiencias significan. Esa decisión no puede ser solamente una fachada. Tiene que ser el sustento real de desarrollar la señalada cultura de buen gobierno corporativo.

En este devenir, la ética empresarial nos lleva, a su vez, hacia la responsabilidad social corporativa, la que supone que la empresa asuma el rol social que le corresponde en relación con su entorno y respecto a los stakeholders o grupos de interés - los inversionistas, los trabajadores, los consumidores y usuarios, los acreedores, el Estado, la comunidad, 
etc. - , lo cual está vinculado estrechamente al régimen constitucional económico de la economía social de mercado. ${ }^{1}$

Juan Pedro Sulbarán explica que la responsabilidad social corporativa se compone de cuatro categorías: la responsabilidad económica (generar utilidades con eficiencia), la responsabilidad legal (respetar las normas y las regulaciones), la responsabilidad ética (actuar más allá de lo estrictamente exigido por las normas) y la responsabilidad filantrópica (contribuir al bienestar de la comunidad). ${ }^{2} \mathrm{Si}$ bien existen varios actores involucrados en la gestión del modelo de responsabilidad social corporativa, para María Laura Estigarribia Bieber el consumidor cumple un rol esencial, pues "además de conocer y exigir sus derechos, debe tener presente que él también tiene una responsabilidad social y considerar el impacto que su conducta tiene en las relaciones de mercado" (2009: 163). No le falta razón a la citada autora, más aún cuando, para la Comisión Europea, "la responsabilidad social empresarial ha evolucionado, en parte, como respuesta a las expectativas y demandas de los consumidores". ${ }^{3}$ Hoy en día, el consumidor es un consumidor responsable: informado de sus derechos y consciente de sus hábitos de consumo. ${ }^{4}$

La responsabilidad social corporativa ha desarrollado diversos criterios para ilustrar la acción social de la empresa, siendo uno de ellos la acción compensatoria, que se refiere a las iniciativas de la empresa que buscan revertir los efectos perjudiciales que su actividad ocasiona respecto al medio ambiente; es decir, se compensa (de ahí el nombre de acción compensatoria) parte de la contaminación ambiental (que se juzga necesaria, atendiendo a las propias circunstancias de la industria),

1 Al respecto, Luis Gallegos Molina (2010: 98) sostiene: “La responsabilidad social empresarial se constituye en el concepto que pretende comprender el sentido y las acciones de reencuentro e integración del empresario y de la empresa con su entorno".

2 Sulbarán (2007: 232-234). En similar sentido encontramos la doctrina del corporate social performance, que procura que la empresa "no solo se mantenga saludable en términos financieros, sino que trata de que se disminuyan los costos sociales y ambientales ligados con su desempeño" (León Untiveros 2010: 297).

3 Cfr. Informe de la Comisión Europea 2002, 347 final, p. 24.

4 En palabras de Carolina de Trazegnies: “La idea no es tener una norma proteccionista que hace la función de 'papá del consumidor' y que hace el trabajo por todos. Considero que debe haber un rol activo del consumidor en cuidar y proteger sus derechos" (2010: 335). 
buscándose el lado positivo a algo que per se es negativo. ${ }^{5}$ Hacemos referencia a la acción compensatoria porque nos ayuda a entender mediante una interpretación extensiva - que hay circunstancias, actividades y hasta productos y servicios que, siendo peligrosos o riesgosos, son (cuando menos hoy en día) necesarios o, incluso, inevitables, de ahí que el derecho no pueda prohibirlos, aunque sí puede exigir que se informe adecuadamente del peligro o el riesgo que conllevan. Esa información ofrecida por la empresa (más allá de que responda a una exigencia estrictamente legal) puede entenderse como parte de su responsabilidad social corporativa, brindándole "un valor agregado a la misma, convirtiéndola en un modelo para empresas idóneas en un mercado con mayores valores y que premia cada vez más este esfuerzo" (Morales Acosta 2011: 69). En palabras de Diego Vega Castro-Sayán: "la voluntariedad de las empresas que decidan trabajar en responsabilidad social empresarial no puede verse alterada por una legislación que eleve costos y altere la economía" (2010: 187).

\section{La información a favor del consumidor como medio idóneo para su protección eficaz}

Alicia Ferrer Montenegro anota que "la relación de consumo refiere a una relación jurídica entre dos sujetos - consumidor y proveedor - que los vincula en calidad de deudor-acreedor" (2010: 233). El detalle está en que dicha relación es, por su propia naturaleza, asimétrica, pues usualmente el proveedor cuenta con mayor y/o mejor información que el consumidor. Carlos Alberto Montaner nos recuerda que "la lucha por la igualdad ante la ley, consagrada en todos los textos legales desde las revoluciones liberales del siglo XVIII, se ha ido depurando y refinando, y hoy, tácitamente, incluye también el derecho que tiene el consumidor a ser tratado con equidad, y sin sufrir el agravio comparativo de que otra persona posea privilegios que a él le son negados" (2004: 9). En sintonía con ese ánimo modernizado de igualdad ante la ley, y en aras de superar la asimetría informativa, la legislación contemporánea ensalza la información a favor del consumidor como un mecanismo idóneo para su protección eficaz.

Actualmente, pues, la información es un derecho consustancial al consumidor, y así lo entiende nuestro Código de Protección y Defensa

5 Para mayores referencias, cfr. Echaiz Moreno (2010: 612-618). 
del Consumidor cuando en el inciso b) de su artículo 1.1 regula el "derecho a acceder a información oportuna, suficiente, veraz y fácilmente accesible, relevante para tomar una decisión o realizar una elección de consumo que se ajuste a sus intereses, así como para efectuar un uso o consumo adecuado de los productos o servicios". La norma referida no hace más que reiterar el criterio expuesto en la jurisprudencia del Indecopi, como puede apreciarse en la Resolución 72-97-TDC, según la cual los proveedores tienen "la obligación de consignar de manera veraz toda la información relevante sobre los productos y servicios ofertados", así como en la Resolución 102-97-TDC, donde se sostiene que "para determinar qué prestaciones y características se incorporan a los términos y condiciones de una operación en caso de silencio de las partes o en caso de que no existan otros elementos de prueba que demuestren qué es lo que las partes acordaron realmente, se acudirá a las costumbres y usos comerciales, a las circunstancias que rodean la adquisición y a otros elementos que se consideren relevantes".

La revaloración del consumidor ha colocado en las manos de este un derecho mínimo: la información oportuna, suficiente, veraz y accesible. Aquí conviene traer a colación las palabras del chef Gastón Acurio: "Nosotros entendimos hace tiempo, como cocineros, que un restaurante no es solo su cocina. Es sobre todo una experiencia. Todo tiene que significar, decir y transmitir emociones. Servicio, comida, discurso, ambiente, valor, son variables igual de importantes. Lo más importante es ser coherente" (Luque 2010: 57). Ante ello subrayamos que para significar, decir y transmitir es fundamental la información. En otro contexto, Steve Ballmer, presidente ejecutivo de Microsoft, anunció el 6 de junio del 2002 que el nuevo objetivo de la corporación era la excelencia, en particular la excelencia en cada punto de la relación con sus clientes, lo cual supondría información de calidad (Slater 2007: 200), pues, como solía decir Walt Disney, "en Disneyland, los visitantes son nuestros invitados" (Capodagli y Jackson 2007: 71). El proveedor que en verdad quiera calificar para tal título deberá procurar que el consumidor tenga a su disposición la correspondiente información; no se trata de tener a un consumidor a ciegas (y retenerlo mientras permanezca así), porque esa será una falsa percepción, tan irreal como efímera, insostenible en el tiempo.

En este orden de ideas, la información "puede ser conceptualizada como un bien, en cuanto tiene un valor económico determinado por las 
circunstancias y por la utilidad que tiene para los particulares" (Bullard 2000: 292), de modo que "el deber de información debe ser entendido como el derecho de los consumidores a recibir de los proveedores toda la información oportuna y necesaria a efectos de tomar una decisión adecuada en la adquisición de productos o prestación de servicios" (Salas Valderrama 2010: 188). Atendiendo a los Lineamientos 2006 de la Ley de Protección al Consumidor, la información antes aludida debe entenderse como la información relevante: "Existe cierta información mínima que, por su relevancia para efectos [de] que el consumidor tome su decisión de consumo, debe ser puesta en conocimiento del consumidor". ${ }^{6}$ Empero hay veces en que la simple información no es suficiente para conseguir la protección eficaz ${ }^{7}$ del consumidor, lo cual ocurre sobre todo tratándose de productos o servicios riesgosos o peligrosos.

\section{La protección eficaz respecto a productos o servicios riesgosos o peligrosos}

La norma glosada establece como uno de los derechos mínimos del consumidor el derecho a la seguridad, que se manifiesta como la "protección eficaz respecto de los productos o servicios que, en condiciones normales o previsibles, representen riesgo o peligro para la vida, salud e integridad física". Algunos autores confunden el alcance de la referida norma al considerar que procura prevenir "todo peligro que pueda causar el consumo de un producto mal fabricado o de un servicio mal realizado" (Carbonell 2010: 87) o que "los proveedores deben tomar las medidas de seguridad, mínimas y previsibles, para reducir los riesgos que puedan perjudicar a los consumidores en las transacciones comerciales que tengan y que puedan repercutir en su salud, seguridad y/o integridad física" (Salas Valderrama 2010: 186). Pero no es este el sentido del artículo examinado: hay que ir más allá y entenderlo aplicable a

6 Lineamientos 2006 de la Ley de Protección al Consumidor, aprobados mediante Resolución 001-2006-LIN-CPC/INDECOPI, de 30 de noviembre del 2006.

7 Felizmente, el legislador se interesa por la "protección eficaz" del consumidor, que debiera ser también importante para la autoridad cuando resuelve el conflicto. Como con acierto sostiene Sergio Huidobro Corbett, "es necesario que los jueces realicen algún estudio económico que les permita acercar a las partes a soluciones más rápidas y eficaces, mediante proposiciones económicas, eficientes y atrayentes" (2005: 25). 
los productos y servicios que por sí mismos son riesgosos o peligrosos, sin tener que llegar al extremo de que su fabricación o prestación hayan sido mal realizadas, ni tener que incidir en el deber mínimo de diligencia esperada del proveedor.

Una comparación del derecho a la seguridad en cuanto a los textos contenidos tanto en la anterior como en la vigente legislación de la materia, puede apreciarse claramente en el siguiente cuadro:

\begin{tabular}{|c|c|}
\hline $\begin{array}{l}\text { Texto Único Ordenado de la Ley del } \\
\text { Sistema de Protección al Consumidor }\end{array}$ & $\begin{array}{l}\text { Código de Protección y Defensa del } \\
\text { Consumidor }\end{array}$ \\
\hline Decreto Supremo 006-2009-PCM & Ley 29571 \\
\hline Norma c & Norma vigente \\
\hline $\begin{array}{l}\text { Artículo 5.- } \\
\text { En los términos establecidos por el pre- } \\
\text { sente Decreto Legislativo, los consumi- } \\
\text { dores tienen los siguientes derechos: } \\
\text { a) Derecho a una protección eficaz con- } \\
\text { tra los productos y servicios que, en } \\
\text { condiciones normales o previsibles, } \\
\text { representen riesgo o peligro para la } \\
\text { salud o la seguridad física. }\end{array}$ & $\begin{array}{l}\text { Artículo } 1 \text {. Derechos de los consumido- } \\
\text { res } \\
\text { 1.1 En los términos establecidos por el } \\
\text { presente Código, los consumido- } \\
\text { res tienen los siguientes derechos: } \\
\text { a) Derecho a una protección eficaz } \\
\text { respecto de los productos y ser- } \\
\text { vicios que, en condiciones nor- } \\
\text { males o previsibles, representen } \\
\text { riesgo o peligro para la vida, } \\
\text { salud e integridad física. }\end{array}$ \\
\hline
\end{tabular}

Del contraste de ambos dispositivos jurídicos se aprecian nítidamente solo tres cambios: primero, se reemplaza "contra los productos y servicios" por "respecto de los productos y servicios", lo que denota una mejor redacción; segundo, se agrega "la vida" como bien jurídico tutelado, lo cual también es pertinente porque se aludía a bienes jurídicos menores (la salud y la seguridad física) y se dejaba de lado un bien jurídico de mayor relevancia (la vida); y tercero, se reemplaza la "seguridad física" por la "integridad física", lo que concuerda con el derecho fundamental de la persona consagrado en nuestra Constitución Política.

Asentados en la normatividad vigente y desmenuzando el texto pertinente, caben hasta 24 casos, si trabajamos con cuatro criterios de clasificación: ofrecimiento, que comprende productos (Prod.) y servicios (Serv.); condiciones, que pueden ser normales (Norm.) y previsibles (Prev.); potencialidad, que abarca riesgo (Riesg.) y peligro (Pelig.); y 
afectación, que subsume vida (Vida), salud (Salud) e integridad física (Integ.). Veamos el siguiente cuadro:

\begin{tabular}{|c|c|c|c|c|c|c|c|c|c|}
\hline \multirow{2}{*}{ N. ${ }^{\circ}$} & \multicolumn{2}{|c|}{ Ofrecimiento } & \multicolumn{2}{|c|}{ Condiciones } & \multicolumn{2}{|c|}{ Potencialidad } & \multicolumn{3}{|c|}{ Afectación } \\
\hline & Prod. & Serv. & Norm. & Prev. & Riesg. & Pelig. & Vida & Salud & Integ. \\
\hline 1 & $\mathrm{x}$ & & $\mathrm{x}$ & & $x$ & & $\mathrm{x}$ & & \\
\hline 2 & $x$ & & $x$ & & $x$ & & & $x$ & \\
\hline 3 & $x$ & & $x$ & & $x$ & & & & $\mathrm{X}$ \\
\hline 4 & $\mathrm{x}$ & & $x$ & & & $x$ & $\mathrm{x}$ & & \\
\hline 5 & $x$ & & $x$ & & & $x$ & & $\mathrm{X}$ & \\
\hline 6 & $\mathrm{x}$ & & $\mathrm{x}$ & & & $x$ & & & $\mathrm{X}$ \\
\hline 7 & $\mathrm{x}$ & & & $x$ & $x$ & & $x$ & & \\
\hline 8 & $x$ & & & $x$ & $x$ & & & $\mathrm{X}$ & \\
\hline 9 & $x$ & & & $x$ & $x$ & & & & $\mathrm{X}$ \\
\hline 10 & $\mathrm{x}$ & & & $x$ & & $x$ & $x$ & & \\
\hline 11 & $x$ & & & $x$ & & $x$ & & $\mathrm{X}$ & \\
\hline 12 & $x$ & & & $x$ & & $x$ & & & $\mathrm{X}$ \\
\hline 13 & & $x$ & $x$ & & $x$ & & $x$ & & \\
\hline 14 & & $x$ & $x$ & & $x$ & & & $\mathrm{X}$ & \\
\hline 15 & & $x$ & $x$ & & $x$ & & & & $\mathrm{X}$ \\
\hline 16 & & $\mathrm{x}$ & $\mathrm{x}$ & & & $x$ & $x$ & & \\
\hline 17 & & $x$ & $x$ & & & $x$ & & $X$ & \\
\hline 18 & & $x$ & $x$ & & & $x$ & & & $X$ \\
\hline 19 & & $x$ & & $x$ & $x$ & & $X$ & & \\
\hline 20 & & $x$ & & $x$ & $x$ & & & $X$ & \\
\hline 21 & & $x$ & & $x$ & $x$ & & & & $\mathrm{X}$ \\
\hline 22 & & $x$ & & $x$ & & $x$ & $x$ & & \\
\hline 23 & & $x$ & & $x$ & & $x$ & & $X$ & \\
\hline 24 & & $x$ & & $x$ & & $x$ & & & $X$ \\
\hline
\end{tabular}

Es decir:

a) Productos que, en condiciones normales, representen riesgo para la vida.

b) Productos que, en condiciones normales, representen riesgo para la salud.

c) Productos que, en condiciones normales, representen riesgo para la integridad física.

d) Productos que, en condiciones normales, representen peligro para la vida.

e) Productos que, en condiciones normales, representen peligro para la salud.

f) Productos que, en condiciones normales, representen peligro para la integridad física.

g) Productos que, en condiciones previsibles, representen riesgo para la vida. 
h) Productos que, en condiciones previsibles, representen riesgo para la salud.

i) Productos que, en condiciones previsibles, representen riesgo para la integridad física.

j) Productos que, en condiciones previsibles, representen peligro para la vida.

k) Productos que, en condiciones previsibles, representen peligro para la salud.

1) Productos que, en condiciones previsibles, representen peligro para la integridad física.

m) Servicios que, en condiciones normales, representen riesgo para la vida.

n) Servicios que, en condiciones normales, representen riesgo para la salud.

o) Servicios que, en condiciones normales, representen riesgo para la integridad física.

p) Servicios que, en condiciones normales, representen peligro para la vida.

q) Servicios que, en condiciones normales, representen peligro para la salud.

r) Servicios que, en condiciones normales, representen peligro para la integridad física.

s) Servicios que, en condiciones previsibles, representen riesgo para la vida.

t) Servicios que, en condiciones previsibles, representen riesgo para la salud.

u) Servicios que, en condiciones previsibles, representen riesgo para la integridad física.

v) Servicios que, en condiciones previsibles, representen peligro para la vida.

w) Servicios que, en condiciones previsibles, representen peligro para la salud.

x) Servicios que, en condiciones previsibles, representen peligro para la integridad física. 
En el tema materia de análisis hay un precedente de observancia obligatoria contenido en la Resolución 095-96-TDC, recaída en el expediente 202-96-CPC y publicada en el diario oficial El Peruano, el 18 de diciembre de 1996, en los siguientes términos:

La razonabilidad de una advertencia, sea que esté referida a los riesgos y peligros que normalmente tienen ciertos productos (es decir, las advertencias a las que alude el segundo párrafo del artículo 9 del Decreto Legislativo 716) o que esté referida a los riesgos y peligros no previstos que se detecten con posterioridad a la colocación de los productos en el mercado (es decir, la obligación de advertir al consumidor, contenida en la última parte del artículo 10 del Decreto Legislativo 716) debe ser analizada en relación a los siguientes elementos básicos:

a) La advertencia debe ser difundida con la debida celeridad. Se deben difundir las advertencias en un plazo prudencial de acuerdo con la gravedad del riesgo o peligro involucrado. Esto implica que, tratándose de un grave daño a la salud de los consumidores, las advertencias deben ser difundidas de inmediato, apenas existan indicios razonables para suponer la existencia del peligro.

b) El uso de un encabezamiento o señal de advertencia adecuados al riesgo o peligro que se advierte. El "título" con el que pretende llamar la atención del consumidor debe ser adecuado para que, sin alarmar innecesariamente, llame la atención lo suficientemente en relación a la magnitud del riesgo al segmento de la población afectada que busca advertirse y permita a los interesados identificar la importancia de la advertencia para ello.

c) El tamaño y frecuencia de la advertencia deben ser adecuados. Las dimensiones de la advertencia y la frecuencia con las que se hace (en el caso que la advertencia se haga por medios de comunicación) deben permitir razonablemente que se llegue a la mayoría de los consumidores afectados.

d) Se debe especificar la naturaleza del riesgo o peligro que se advierte. Esto implica señalar si estamos, por ejemplo, frente a un riesgo a la salud, o a la propiedad del consumidor, o simplemente puede implicar la pérdida del producto adquirido. Por ejemplo, si un producto es tóxico si se bebe o dañino si se aplica sobre los ojos, debe indicarse tales efectos. 
e) Debe utilizarse un lenguaje accesible y entendible por un consumidor razonable. Debe por tanto descartarse el uso de lenguaje excesivamente técnico o científico, utilizándose por el contrario términos que permitan al consumidor entender cuáles son los riesgos o peligros que se le advierten.

f) Se debe describir el nivel de incertidumbre que rodea al riesgo o peligro previsible. Si el riesgo es solo potencial o no se tiene certeza absoluta del mismo, puede indicarse ello en el aviso, pudiendo en estos casos usarse expresiones condicionales. Por el contrario, si se trata de un riesgo cierto y preciso, debe utilizarse un lenguaje que dé a entender ello al consumidor.

g) Deben explicarse las medidas que se deben adoptar para evitar el riesgo o para mitigar los efectos que pudieran producirse. La advertencia debe, de ser posible, señalar cómo corregir estos problemas de una manera clara y sencilla.

Este precedente, de observancia obligatoria (pronunciado a propósito de un caso que, en verdad, se refirió a un riesgo injustificado [Atoche 2007: 79]), está hoy recogido en el Código de Protección y Defensa del Consumidor, en el capítulo IV (Salud y seguridad de los consumidores), subcapítulo I (Protección a la salud y seguridad de los consumidores), específicamente en los artículos 25 (deber general de seguridad), 26 (medidas de los proveedores frente a los riesgos previstos), 27 (información de productos o sustancias peligrosas), 28 (medidas de los proveedores para eliminar o reducir los peligros no previstos) y 29 (criterios aplicables a la información y advertencia sobre el riesgo y la peligrosidad).

Los productos de tabaco y las bebidas alcohólicas sirven para ilustrar los supuestos reseñados en líneas anteriores. Sin perjuicio de otros casos, igualmente interesantes - respecto a productos (como los insumos químicos, los medicamentos y los plaguicidas) o respecto a servicios (como los servicios médicos en una intervención quirúrgica, que exige el consentimiento informado $\left.{ }^{8}\right)-$, nos referiremos a los productos mencionados.

Podemos categorizar los productos de tabaco como aquellos que, en condiciones normales, representan peligro para la vida y la salud (Pini-

8 Cfr. Amaya Ayala (2010: 160). Véase también la Resolución 169-2002-CPC, respecto al caso de la cirugía estética. 
llos et al. 2005). Precisamente, atendiendo a dicha realidad, en los últimos años se produjo una ola legislativa regulatoria de los productos de tabaco, pudiendo citarse la Ley 25357 (de 1993, que prohibió fumar en espacios cerrados de uso público), la Ley 26739 (de 1996, que regula la publicidad de cigarrillos en la televisión y la radio), la Ley 26849 (también de 1996, que prohíbe la venta y la publicidad de productos de tabaco en lugares de acceso público), la Ley 26957 (de 1998, que prohíbe la venta de productos de tabaco a menores de edad) y la Ley 28705 (del 2006, que derogando todas las anteriores estableció medidas para la prevención y el control de los riesgos del consumo del tabaco).

Merece especial mención el Reglamento de la Ley 25357, aprobado mediante el Decreto Supremo 083-93-PCM, que estableció en su artículo 7: “Las cajetillas, paquetes o bolsas de productos de tabaco deberán de llevar de manera ampliamente legible, ocupando no menos de la décima parte del área total del empaque, la frase 'Fumar es dañino para la salud, está prohibido fumar en lugares públicos, según la Ley № 25357'". Esta norma se encuentra derogada, pero tiene el mérito de haber sido pionera en imponer el citado texto en los empaques de los productos de tabaco. Hoy está vigente el Reglamento de la Ley 28705, aprobado mediante el Decreto Supremo 015-2008-SA (modificado posteriormente por el Decreto Supremo 001-2010-SA y, recientemente, por el Decreto Supremo 001-2011-SA), que estipula en su artículo 22.2 que deberán incluirse frases que constituyen advertencias sanitarias y que son las siguientes:

a) Fumar causa gangrena.

b) Fumar causa cáncer de mama.

c) Fumar causa impotencia sexual.

d) Fumar causa aborto.

e) Fumar causa cáncer de pulmón.

f) El humo del tabaco causa asma en los niños.

g) El humo de tabaco daña a tu bebé.

h) La nicotina es tan adictiva como la heroína.

i) Fumar causa infarto al corazón.

j) Fumar causa cáncer de laringe.

k) Fumar causa infarto cerebral.

l) Fumar causa ceguera. 
En cuanto a las bebidas alcohólicas, estas pueden categorizarse como productos que, en condiciones previsibles, representan riesgo para la vida, la salud y la integridad física. La Ley 28681 prescribe en su artículo 7: "En un espacio no menor del 10\% del área total del empaque, envolturas o afines, así como en las etiquetas de los envases que se utilicen para la comercialización de cualquier bebida alcohólica, se consignará en caracteres legibles la siguiente frase: 'Tomar bebidas alcohólicas en exceso es dañino'".

Entonces, puede apreciarse que la producción, la comercialización y la publicidad de los productos de tabaco y de las bebidas alcohólicas son lícitas, pero el consumo de estos representa - en condiciones normales o previsibles - riesgo o peligro para la vida, la salud y la integridad física, según lo anteriormente explicado. De ahí que la legislación de la materia exija ir más allá de la información que todo proveedor debe ofrecer a los consumidores, normando específicamente los textos y las características de dicha información, en procura de conseguir una protección eficaz de estos últimos.

\section{Conclusiones}

1. La importancia de la protección del consumidor reposa en dos claras razones: por un lado, la superación de la antigua dicotomía "parte fuerte - parte débil" en la contratación; y por otro, el reconocimiento de la asimetría informativa en la relación de consumo.

2. El actual régimen constitucional económico contenido en nuestra Constitución Política tiende a la protección del consumidor, sin que ello suponga una actuación paternalista que, lejos de ser beneficiosa, termina siendo contraproducente para todos los que de una u otra manera están involucrados en el mercado.

3. El gobierno corporativo, la ética empresarial y la responsabilidad social corporativa son los nuevos referentes para la actuación de las empresas en el mercado, que, entre otras cuestiones, hacen énfasis en la revaloración del rol del consumidor.

4. La revaloración del consumidor hace posible que este haya ganado, cuando menos, un derecho mínimo, cual es la información oportuna, suficiente, veraz y accesible. Pero hay veces en que la simple información no es suficiente para conseguir la protección 
eficaz del consumidor, lo cual ocurre sobre todo con relación a productos o servicios riesgosos o peligrosos.

5. El derecho de seguridad es aplicable a los productos y servicios que por sí mismos son riesgosos o peligrosos, sin tener que llegar al extremo de que su fabricación o prestación hayan sido mal realizadas, ni tener que incidir en el deber mínimo de diligencia esperada del proveedor.

6. La producción, la comercialización y la publicidad de los productos de tabaco y de las bebidas alcohólicas son lícitas, pero el consumo de estos representa, en condiciones normales o previsibles, riesgo o peligro para la vida, la salud y la integridad física; de ahí que la legislación de la materia exija información específica y norme los textos y las características de esta, en procura de conseguir una protección eficaz de los consumidores.

\section{Bibliografía}

Amaya Ayala, Leoni Raúl (2010). “El nuevo marco legal sobre protección al consumidor". Manual de actualización comercial 4. Lima: Gaceta Jurídica.

Atoche Fernández, Paola (2007). Precedentes de observancia obligatoria del Indecopi. Lima: Grijley.

Bullard González, Alfredo (2000). La asimetría de información en la contratación a propósito del dolo omisivo. Lima: Palestra.

Capodagli, Bill y Lynn Jackson (2007). La gestión al estilo Disney: cómo aplicarla a su empresa. Barcelona: Deusto.

Carbonell O’Brien, Esteban (2010). Análisis al Código de Protección y Defensa del Consumidor. Lima: Jurista.

Echaiz Moreno, Daniel (2010). "La responsabilidad social corporativa para la protección de los stakeholders". Instituciones de derecho empresarial. Lima: Asociación Peruana de Ciencias Jurídicas y Conciliación (APECC).

Estigarribia Bieber, María Laura (2009). “La responsabilidad social. Un compromiso que debe ser asumido por partida doble: empresa y consumidor". Lex. Año VII, núm. 6. Lima: Facultad de Derecho y Ciencia Política de la Universidad Alas Peruanas. 
Ferrer Montenegro, Alicia (2010). "El consumidor, su endeudamiento y la insuficiencia legal de su protección". Revista de Derecho Comercial. 3. ${ }^{a}$ época. Núm. 3. Montevideo: Instituto de Derecho Comercial de la Facultad de Derecho de la Universidad de la República.

Gallegos Molina, Luis (2010). Economía social de mercado, medio ambiente y responsabilidad social empresarial. Lima: Instituto de Estudios Social Cristianos/ Fundación Konrad Adenauer Stiftung.

Huidobro Corbett, Sergio (2005). "Justicia y economía". Revista de Derecho de la Empresa 4. Santiago: Facultad de Derecho de la Universidad Adolfo Ibáñez/ Legis..

León Untiveros, Miguel Ángel (2010). “La responsabilidad social corporativa en el Perú. Realidad versus discurso". Foro Jurídico 11. Lima: Facultad de Derecho de la Pontificia Universidad Católica del Perú.

Lineamientos 2006 de La Ley de Protección al Consumidor, aprobados mediante Resolución 001-2006-LIN-CPC/INDECOPI, de 30 de noviembre del 2006.

Luque, Julio (2010). Gastón Acurio. La marca del movimiento gastronómico peruano. Lima: El Comercio.

Martínez-Ortiz, Juan José (2007). “El gobierno corporativo en el Perú: contribución para enfocar el concepto". Revista de Economía y Derecho 14. Lima: Sociedad de Economía y Derecho de la Universidad Peruana de Ciencias Aplicadas.

Montaner, Carlos Alberto (2004). "El comercio libre, los precios y los derechos de los consumidores". Revista de Economía y Derecho. Lima: Sociedad de Economía y Derecho de la Universidad Peruana de Ciencias Aplicadas.

Montoya Chávez, Victorhugo (2009). "Principios rectores de la Constitución económica". Foro Jurídico. Año IX, núm. 9. Lima: Facultad de Derecho de la Pontificia Universidad Católica del Perú.

Morales Acosta, Alonso (2011). Responsabilidad social y buen gobierno corporativo. Lima: Asesorandina Publicaciones.

Pinillos, Luis et al. (2005). "Tabaquismo: un problema de salud pública en el Perú". Revista Peruana de Medicina Experimental y Salud Pública 22. Lima. $<$ http://www.scielo.org.pe/scielo.php?script=sci_artte xt\&pid=S1726-46342005000100010>. 
Quispe Correa, Alfredo (2007). La Constitución económica. 2. a edición. Lima: MaxiGraphica Impresores.

Salas Sánchez, Julio (2008). "Gobierno corporativo" (entrevista). IurisConsulto. Año I, núm. 1. Lima: Carrera de Derecho de la Universidad San Ignacio de Loyola.

Salas Valderrama, Rodolfo Alejandro (2010). "Algunos apuntes y reflexiones sobre la tutela de los derechos de los consumidores y la asimetría informativa en el mercado". Foro Jurídico 11. Lima: Facultad de Derecho de la Pontificia Universidad Católica del Perú.

Slater, Robert (2007). El relanzamiento de Microsoft. Cómo reinventaron su empresa Bill Gates y Steve Ballmer. Barcelona: Deusto.

Sulbarán, Juan Pedro (2007). “El concepto de responsabilidad social de la empresa". Revista Economía 10. Caracas: Facultad de Ciencias Económicas y Sociales de la Universidad de los Andes.

Trazegnies, Carolina de (2010). “Sobre la publicación del Código de Protección y Defensa del Consumidor: perspectivas y análisis (entrevista)". Foro Jurídico 11. Lima: Facultad de Derecho de la Pontificia Universidad Católica del Perú.

Vega Castro-Sayán, Diego (2010). “Responsabilidad social empresarial, paternalismo y legislación". Constitución, economía y empresa en el Perú. Lima: Fondo Editorial de la Universidad Peruana de Ciencias Aplicadas. 